\title{
A surgical approach for a cochlear implant: An anatomical study
}

\author{
By Graeme M. Clark (Melbourne)
}

\section{Introduction}

THERE is now increased interest in the possibility of restoring brain and nerve function by applying recent developments in electronics and current knowledge of neurophysiology. This is evident from the research being undertaken to see whether a visual cortical implant can help blind patients, and whether electrical stimulation of the auditory pathways can help patients with severe loss of hearing.

In order to reproduce the pitch of a sound, electrical stimulation should be carried out in accordance with the volley or place theories of pitch perception. Recent studies (Clark et al., I973) have shown, however, that there are limitations to electrical stimulation on a rate basis. Therefore, if we are going to reproduce speech by electrical stimulation and help deaf people communicate, we must also stimulate on a place basis. This means that it will be necessary to implant a number of electrodes close to different groups of auditory nerve fibres.

Simmons (I966) has implanted an array of electrodes close to the terminal auditory nerve fibres in the modiolus of a patient, and stimulated different groups of fibres electrically. The results were not entirely satisfactory as the patient had difficulty understanding speech. This may have been due to the fact that when electrodes are implanted in the modiolus, it is difficult to place them close to appropriate nerve fibres. Furthermore, the insertion of the electrodes is likely to destroy nerve fibres and this will prevent information reaching the higher brain centres.

In order to overcome some of these difficulties, a series of anatomical dissections have been carried out on human temporal bones to see if there is an alternative surgical approach to the terminal auditory nerve fibres. As a result, it has been shown that access can be obtained to the nerve fibres which normally convey frequency information from the lateral aspects of the basal, middle and apical turns of the cochlea.

\section{Methods}

Dissections have been carried out on ten human temporal bones. The mastoid air cells were removed, the facial nerve exposed, the posterior meatal wall lowered, the bone overlying the turns of the cochlea removed, 


\section{G. M. Clark}

and the internal carotid artery exposed medial to the bony Eustachian tube. The relations of the helicotrema, modiolus and cochlear turns to important anatomical structures such as the oval and round windows, facial nerve, processus cochleariformis and opening of the Eustachian tube were determined. More precise measurements of some of these relations were also made using calipers and a scale.

\section{Results}

The relations of the osseous cochlea and vestibule to the structures of the medial wall of the tympanum are shown diagrammatically in Figure I.

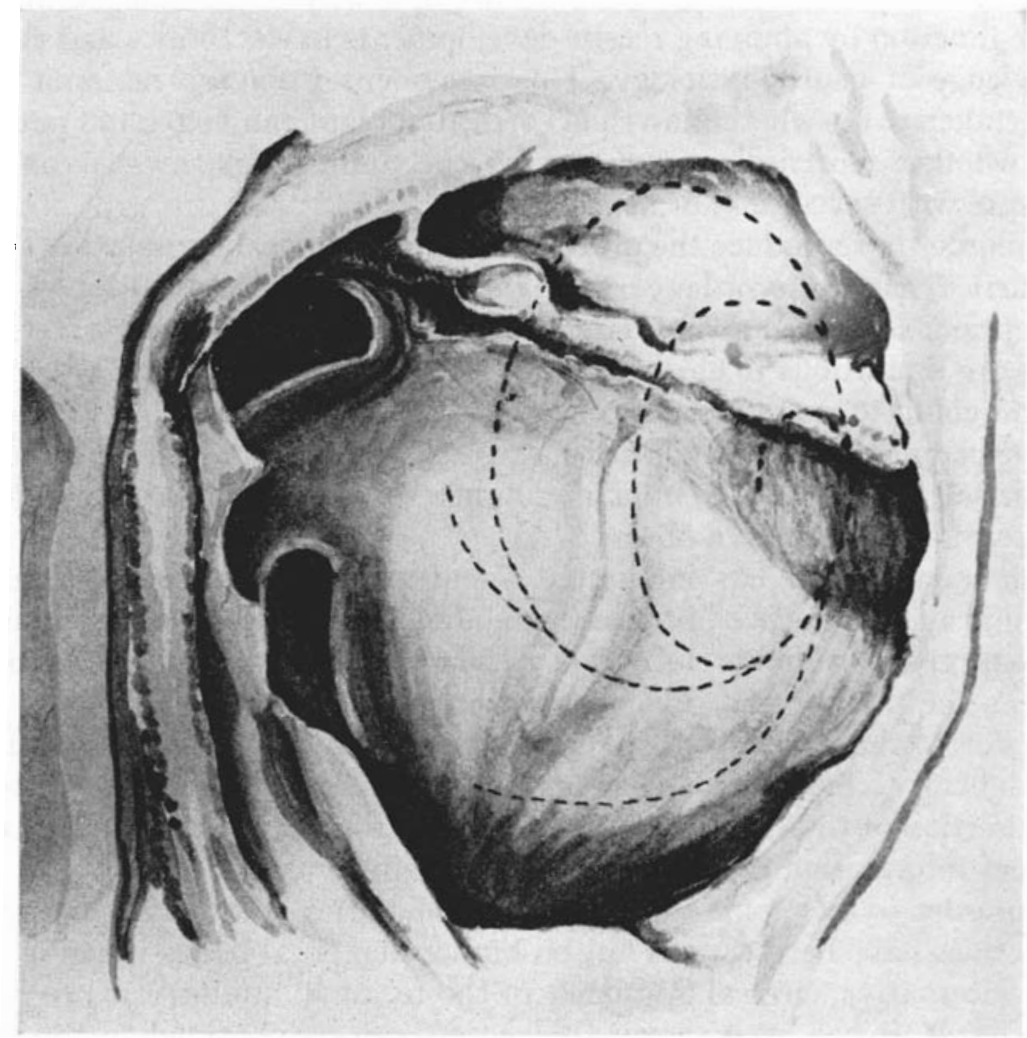

FIG. I.

The medial wall of the tympanum. The underlying osseous vestibule and cochlea are delineated by the interrupted lines.

It should be noted that the horizontal portion of the facial nerve overlies the vestibule superiorly, and the genu is anterosuperior to the processus cochleariformis. The processus cochleariformis is separated from the oval window by a recess and overlies the posterior margin of the distal portion 


\section{A surgical approach for a cochlear implant}

of the basal cochlear turn. The helicotrema is also along a line drawn through the centre of the oval window, and approximately at right angles to a line between the centres of the oval and round windows.

Detailed measurements were made of the distances of the helicotrema and the margins of the osseous spiral lamina in the distal portions of the basal and middle cochlear turns from the centre of the oval window, when measured along a line from the centre of the oval window to the helicotrema. This is illustrated in Figure $2(a)$ where $\mathrm{H}$ refers to the helicotrema,

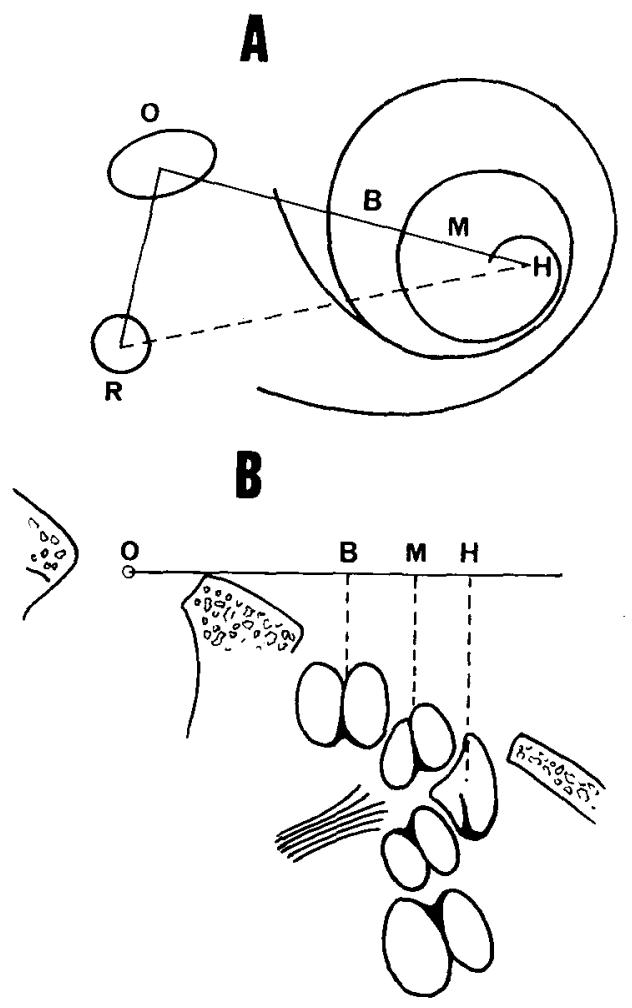

FIG. 2.

(a) Diagram of the osseous vestibule and cochlea: $H$, helicotrema; $M$, free margin of osseous spiral lamina in the distal portion of the middle turn of the cochlea; $B$, free margin of osseous spiral lamina in the distal portion of the basal turn of the chochlea; $O$, fenestra vestibuli; $R$, fenestra cochlear. Measurements were made along the line $O, H . R, H$ is defined as the line of demaracation between the basal, middle and apical turns of the cochlea.

(b) Diagram of the plane in which measurements were made of the projection of the cochlea.

and $\mathrm{M}$ and $\mathrm{B}$ the margins of the osseous spiral lamina in the distal portions of the middle and basal turns respectively. The measurements made were of the projection of the cochlea as viewed from above, and this can be seen in Figure 2(b). It should also be noted that the demarcation between the apical, middle and basal turns is defined as the line $\mathrm{R}, \mathrm{H}$ between the centre 


\section{G. M. Clark}

of the round window and the helicotrema. Measurements were made of the depth of the bone overlying the proximal portion of the basal turn I mm. anterior to the round window, and the distal portions of the basal and middle turns at points along a line drawn between the helicotrema and the oval window. The length of the proximal and distal portions of the basal turn, and the distal portion of the middle turn that could in practice be exposed by drilling away the overlying bone were also determined. All these measurements are recorded in Table I. From this it can be seen that, in the projection of the cochlea, the distance from the centre of the oval window to the helicotrema was $4.6 \mathrm{~mm}$., to the spiral lamina in the distal portion of the middle turn $4 . \mathrm{Imm}$., and to the spiral lamina in the distal portion of the basal turn $2.5 \mathrm{~mm}$. The depth of bone overlying the proximal portion of the basal turn was $\mathrm{I} \cdot 3 \mathrm{~mm}$. the distal portion of the basal turn $\mathrm{I} \cdot 9 \mathrm{~mm}$. and the distal portion of the middle turn $\mathrm{I} \cdot 7 \mathrm{~mm}$. The length of the proximal portion of the basal turn exposed was $3.6 \mathrm{~mm}$., the distal portion of the basal turn $2 \cdot 7 \mathrm{~mm}$., and the distal portion of the middle turn $2 \cdot \mathrm{I} \mathrm{mm}$.

TABLE I.

\begin{tabular}{|c|c|c|}
\hline & $\begin{array}{c}\text { Average } \\
(\mathrm{mm} .)\end{array}$ & $\begin{array}{l}\text { Range } \\
(\mathrm{mm} .)\end{array}$ \\
\hline Distance oval window to helicotrema & $4 \cdot 6$ & $4 \cdot 5-4 \cdot 8$ \\
\hline Distance oval window to distal portion middle turn & $4 \cdot 1$ & $4 \cdot 0-4 \cdot 3$ \\
\hline Distance oval window to distal portion basal turn & $2 \cdot 5$ & $2 \cdot 5 \cdot 2 \cdot 5$ \\
\hline Depth of bone overlying proximal portion basal turn & $1 \cdot 3$ & $0 \cdot 8-\mathbf{I} \cdot 7$ \\
\hline Depth of bone overlying distal portion basal turn & $I \cdot 9$ & $1 \cdot 3-2 \cdot 0$ \\
\hline Depth of bone overlying distal portion middle turn & $1 \cdot 7$ & $I \cdot 3-2 \cdot I$ \\
\hline Length exposed of proximal portion basal turn & $3 \cdot 6$ & $2 \cdot 5-4 \cdot 8$ \\
\hline Length exposed of distal portion basal turn & $2 \cdot 7$ & $2 \cdot 0-3 \cdot 5$ \\
\hline Length exposed of distal portion middle turn & $2 \cdot I$ & $2 \cdot 0-2 \cdot 5$ \\
\hline
\end{tabular}

\section{Discussion}

It should be emphasized that at the moment the possibility of using a cochlear implant needs to be reversed for patients with little or no residual hearing. As the use of a hearing implant has not been fully explored it should not be offered to patients with some residual hearing as a powerful hearing aid can probably provide better communication. Furthermore, if an electrode is implanted in the cochlea of a patient with some residual hair cells, the patient will experience hearing through the electrophonic effect, and there is a risk that hearing will be lost through damage to the remaining hair cells.

Nevertheless, there is a significant group of patients with very severe or total hearing loss in whom a hearing aid is of no value. These patients usually need some further assistance in perceiving speech, and the development of a satisfactory cochlear implant would be of great value to them.

A cochlear implant is not the only way to help these patients; however, it is more likely to be of benefit than other types of vocoders for two 


\section{A surgical approach for a cochlear implant}

reasons. Firstly, there are inbuilt neurophysiological mechanisms in the higher auditory centres which make the auditory system suited for the perception of complex speech signals. Secondly, patients who have lost hearing after birth have usually developed templates for speech-pattern recognition along their auditory pathways.

It is unlikely that all the tonal qualities of sound will be reproduced by a hearing implant, as behavioural studies in cats (Clark, I973) have shown that with electrical stimulation it is not possible to reproduce difference limens for sound frequencies except at low rates of stimulation. Furthermore, the complicated innervation of the outer hair cells cannot be easily simulated by an electrode array. Nevertheless, there is considerable redundancy in the speech signal, and for this reason electrical stimulation using both the volley and place principles could provide communication for patients with total hearing loss.

The simplest way of placing a large number of electrodes close to discrete groups of auditory nerve fibres would be to pass an electrode array through the round window and around the coils of the cochlea. Experimental studies by the author using a variety of different types of electrodes have shown, however, that it is very difficult to carry out this manipulation.

For this reason it would be necessary to make a limited number of openings into the cochlea for inserting electrode arrays. Consequently, the present study has been undertaken to determine whether the basal, middle and apical coils of the cochlea are readily accessible if the overlying bone is drilled away, and whether important anatomical structures such as the facial nerve and carotid artery would restrict the surgical approach.

The present study has shown that direct access can be obtained to the proximal and distal portions of the basal turn, and the distal portion of the middle turn for a total length of $8 \mathrm{~mm}$.

Direct implantation of electrodes at a number of points along the cochlear, however, is not likely to be as satisfactory as making a small opening into the proximal and distal portions of the basal turn and the distal portion of the middle turn, and threading electrode arrays along the three cochlear turns as illustrated in Figure 3.

It is envisaged that in order to carry out this implantation a two-stage operation should be performed. The first stage would be a modified radical mastoidectomy, and the second stage should commence when the mastoid cavity has healed. After the electrodes are implanted in the cochlea they should be brought through a tunnel in the facial ridge, and connected to the radio receiver which could lie in the mastoid cavity as illustrated in Figure 4 .

\section{Summary}

This study has demonstrated the anatomical relations of the cochlea to structures in the medial wall of the tympanum, and has shown that 


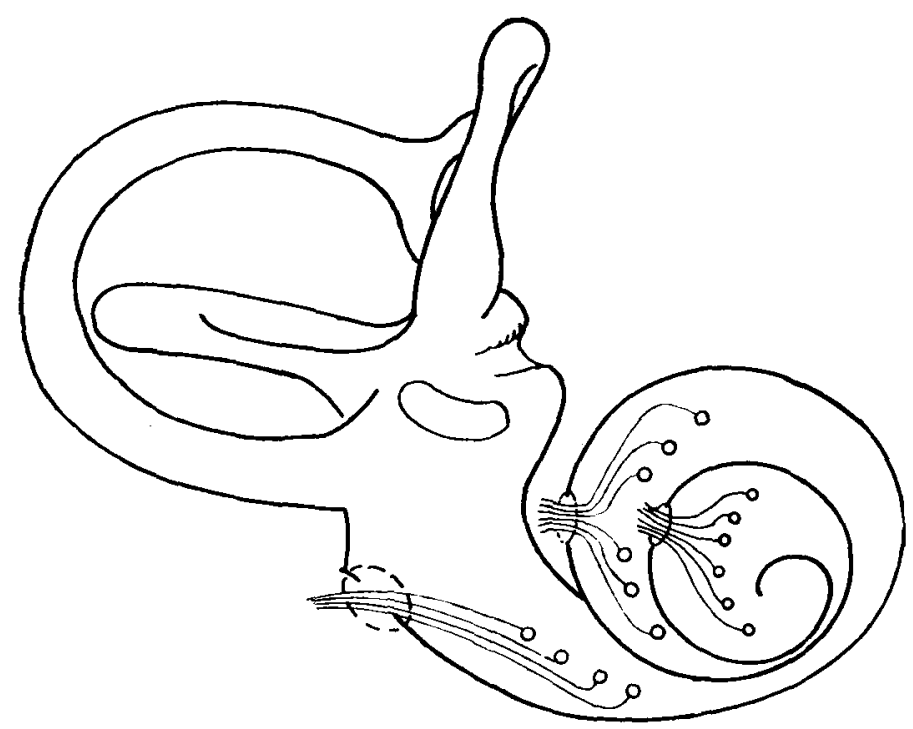

FIG. 3 .

A diagram of the osseous labyrinth showing electrode arrays implanted in the basal, middle and apical turns of the cochlea.

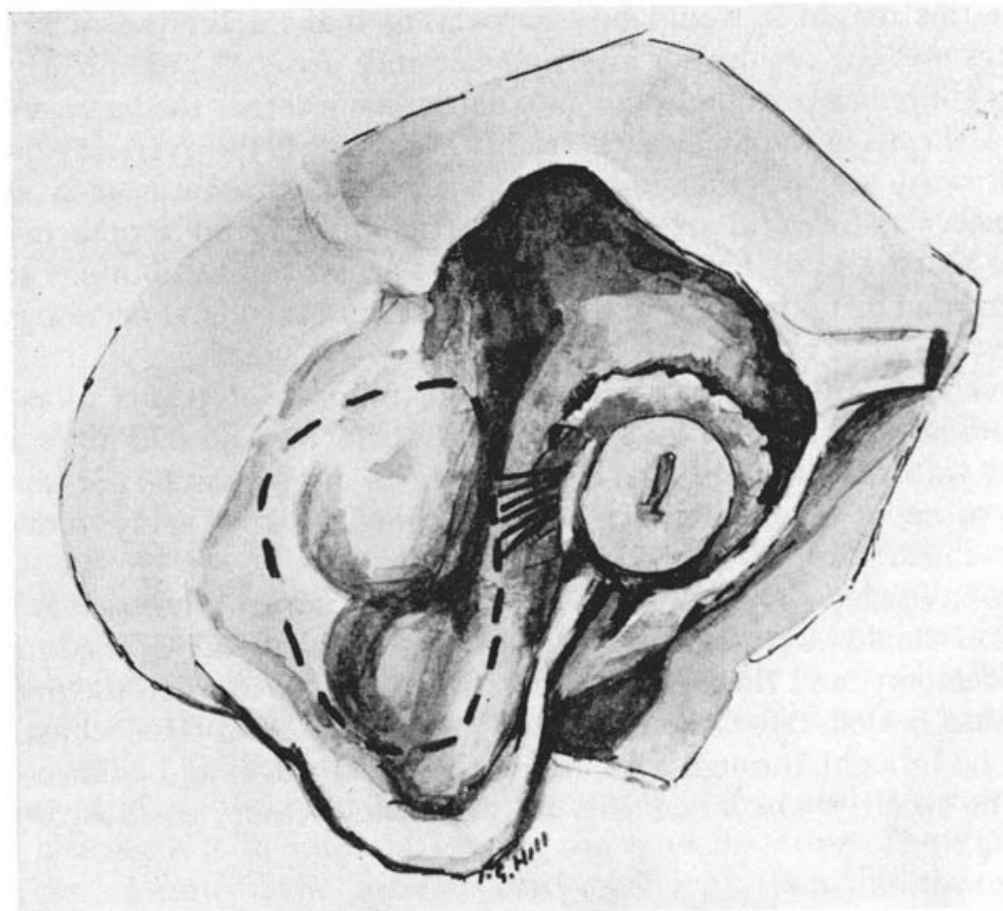

FIG. 4.

The proposed surgical approach for a cochlear implant showing the modified radical mastoid cavity and tympanomeatal flap. The placement of the receiver and electrode wires are indicated by the interrupted line. 


\section{A surgical approach for a cochlear implant}

surgical access can be obtained to the terminal auditory nerve fibres supplying the basal, middle and apical turns of the cochlea.

It is suggested that a cochlear implantation should be carried out in two stages. The first stage should be a modified radical mastoidectomy, and in the second stage electrode arrays should be implanted into the three cochlear turns through openings made in the proximal and distal portions of the basal turn, and the distal portion of the middle turn.

\section{Acknowledgements}

This reasearch has been supported by the Channel O Nerve Deafness Appeal. I would also like to thank Mr. R. J. Walkerden for technical assistance and Miss F. Hill and Mr. G. Hillas for the artwork.

\section{REFERENCES}

CLARK, G. M. (1973) Journal of Laryngology and Otology, 87, 929.

一, Kranz, H. G., and Minas, H. (1973) Experimental Neurology, 41, 190.

Simmons, F. B. (1966) Archives of Otolaryngology, 84, 2.

G. M. Clark,

Department of Otolaryngology,

University of Melbourne,

Parkville,

Victoria,

Australia. 


\section{University Library}

\section{- M M I N E R VA A gateway to Melbourne's research publications}

Minerva Access is the Institutional Repository of The University of Melbourne

Author/s:

Clark, Graeme M.

Title:

A surgical approach for a cochlear implant: an anatomical study

Date:

1975

Citation:

Clark, G. M. (1975). A surgical approach for a cochlear implant: an anatomical study. Journal of Laryngology and Otology, 89(1), 9-15.

Persistent Link:

http://hdl.handle.net/11343/27150 